\title{
Charity begins at home: A message to the $\mathrm{CAG}$ membership
}

$\mathrm{D}_{\mathrm{a}}^{\mathrm{i}}$ id you know that over $90 \%$ of charitable donations arise from individuals, compared with the less than $10 \%$ from corporate sponsorship? Of the $\$ 4.6$ billion receipted charitable donations per annum, $20 \%$ is directed toward health-related organizations. When you are approached to give a donation, have you really considered what issues determine whether and how much you will give? Is it the organization and the work that it does? Is it self interest? Has the organization's work had an impact on your personal or professional life? Is your decision an emotional one?

Professional polling organizations have researched this issue and have found that, in general, people donate to causes or issues that affect or have affected their lives. For example, individuals and groups support their religious institutions; professionals donate to organizations that support work relating to issues in which they are involved. The success of the Heart and Stroke Foundation, Diabetes Foundation and Kidney Foundation can be directly attributed to the energy and financial commitment of countless numbers of physicians and surgeons, patients and families who have a commitment to finding solutions to the diseases that these agencies represent.

The Canadian Digestive Disease Foundation (CDDF) enters a new phase of growth with the mandate to provide patient education programs, programs to educate the government and monies for research to find 'cures' for diseases of the digestive system. You should be aware that the pharmaceutical industry, in particular AstraZeneca Canada Inc, has been extremely generous in the early growth of the CDDF. Other pharmaceutical and nonpharmaceutical companies are also stepping forward to help the CDDF reach its goals. The CDDF now has an interactive Web site (www.cddf.ca). This will provide the membership of the CAG with educational materials for their patients (copies can be printed from the Web site), as well as a credible site to direct patients for further information. These materials were produced due to the commitment of members of the $\mathrm{CAG}$ and, in particular, Alan Cockeram and his Education Committee. The site is also designed to personalize information for visitors regarding their particular area of interest, as well as capture information toward the better understanding of digestive diseases across Canada. The CDDF now has a National Office located in proximity to the CAG National Office, with a part-time National Office Manager, Sandra Daniels, and Executive Director, Paul Sinclair.

The CAG membership has received information on the CDDF and a request for financial support. We all make charitable contributions. Why not give directly to an agency that supports the work and issues that we believe in? I ask all of you to be generous and give to the CDDF. If we are to improve the lives of people with diseases of the gastrointestinal system, we ourselves must commit.

CDDF National Office
2902 South Sheridan Way
Oakville, Ontario L6J 7L6
Telephone: 905-829-3949
Toll free: $866-819-2333$
Fax: $905-829-3958$
E-mail: cddfoffice@cddf.ca

GA Levy MD FRCPC President, Canadian Digestive Disease Foundation

\section{Information and details for the 2002 Canadian Digestive Diseases Week available on the CAG Web site http://www.cag-acg.org}




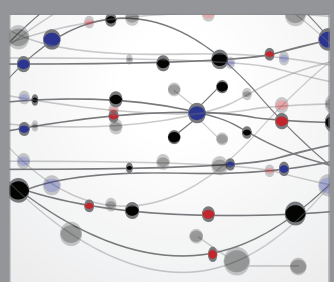

The Scientific World Journal
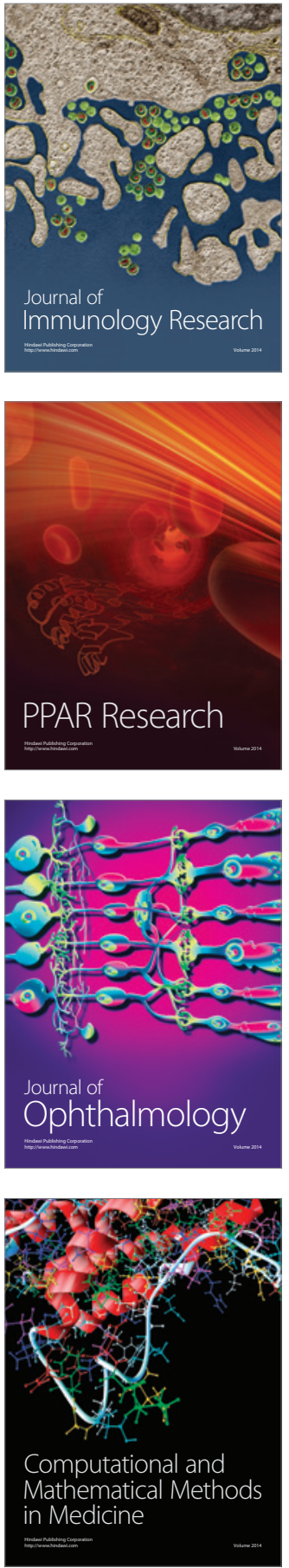

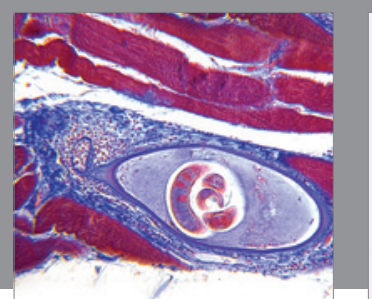

Gastroenterology Research and Practice

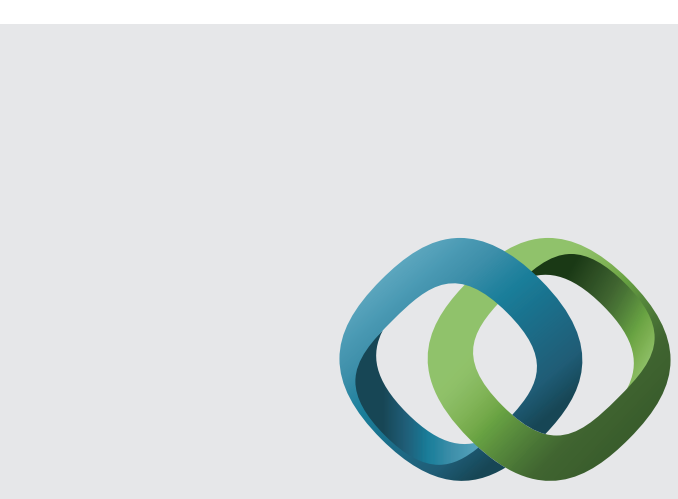

\section{Hindawi}

Submit your manuscripts at

http://www.hindawi.com
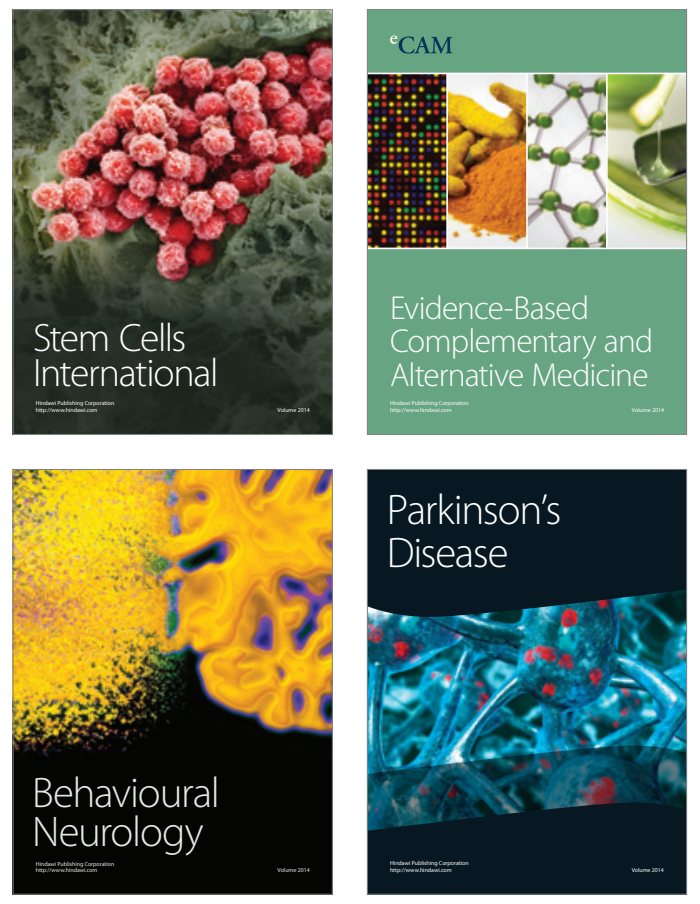
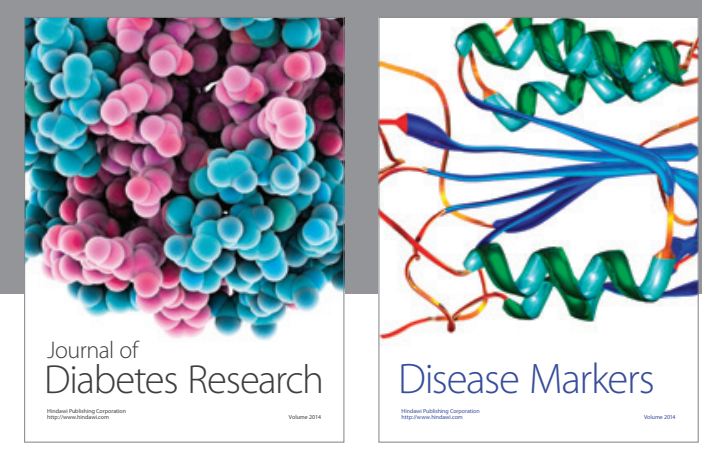

Disease Markers
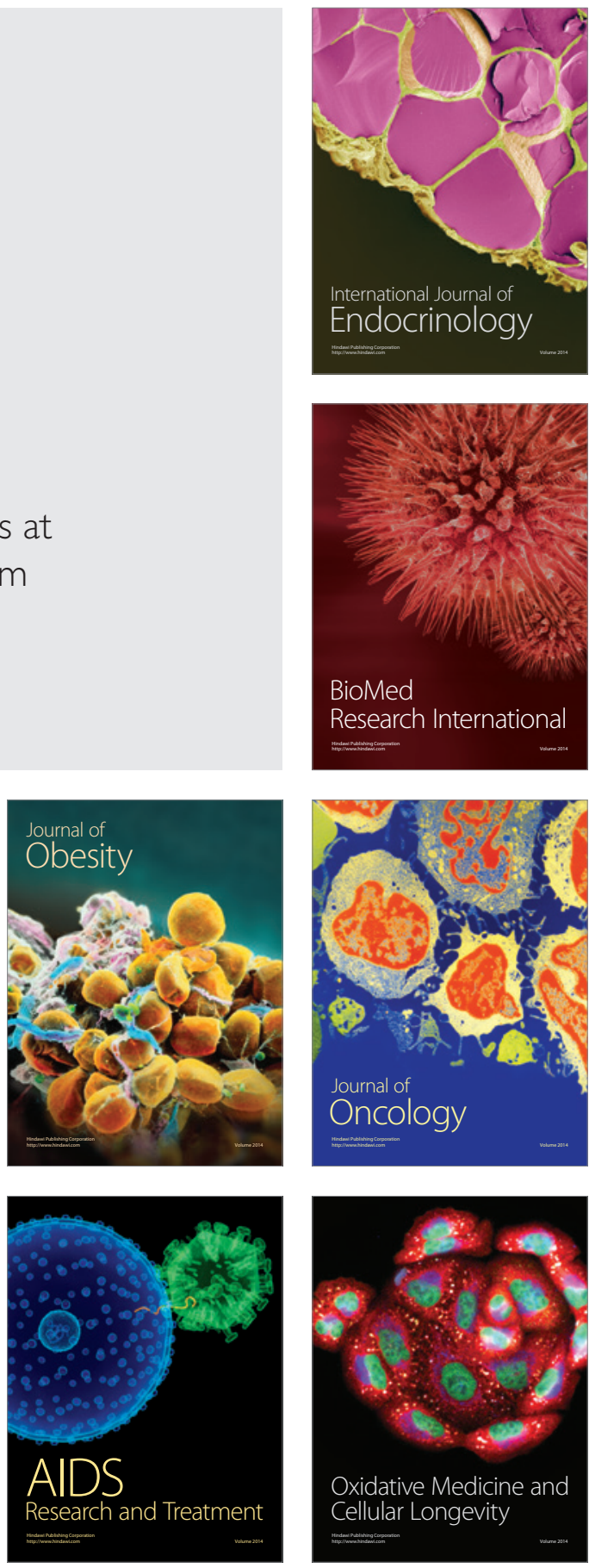